\title{
Perbandingan Metode Simple Additive Weighting (SAW) dan ELECTRE Dalam Pemilihan Tempat Kos di Area Kampus Purwokerto
}

\author{
Corie Mei Hellyana ${ }^{1}$, Warjiyono ${ }^{2}$ \\ ${ }^{1}$ Prodi Sistem Informasi, Universitas Bina Sarana Informatika \\ ${ }^{2}$ Program Studi Sistem Informasi Akuntansi, Universitas Bina Sarana Informatika \\ ${ }^{1}$ corie.cma@bsi.ac.id, ${ }^{2}$ warjiyono.wrj@bsi.ac.id
}

\begin{abstract}
Boarding house is the second place to live after living with parents. Boarding houses are usually chosen by someone who lives far from parents with the interests of studying or working. But in general boarding houses are identical to someone who is in school or college. With the many universities or educational institutions in the city of Purwokerto, many people rent their houses as boarding houses. But sometimes many boarding house residents move around for various reasons, such as rising boarding prices, far from the place of study, far from public facilities and so on. Therefore, it is necessary to choose a boarding house to reduce boarding house occupants who move. In choosing this boarding house, ELECTRE and SAW methods are used as tools to get a picture of the best boarding houses. With this method the weighting is done to get the percentage of matches for the recommended boarding house according to the criteria.
\end{abstract}

Keywords: boarding, Electre, SAW, criteria

Abstrak - Rumah kost merupakan tempat tinggal kedua setelah tempat tinggal bersama orang tua. Rumah kost biasanya dipilih oleh seseorang yang tinggal jauh dari orang tua dengan kepentingan belajar atau bekerja. Tetapi secara umum rumah kos identik dengan seseorang yang sedang bersekolah atau kuliah. Dengan banyaknya perguruan tinggi atau lembaga pendidikan di kota Purwokerto, maka banyak masyarakat yang menyewakan rumahnya sebagai tempat kos. Namun terkadang banyak penghuni kos yang berpindah-pindah dengan berbagai alasan, misalnya kenaikan harga kos, jauh dari tempat kuliah, jauh dari fasilitas umum dan lain sebagainya. Oleh karena itu perlu dilakukan pemilihan tempat kos untuk mengurangi penghuni kos yang berpindah tempat. Dalam pemilihan tempat kos ini digunakan metode ELECTRE dan SAW sebagai tools untuk mendapatkan gambaran tempat kos yang terbaik. Dengan metode ini dilakukan perankingan bobot untuk mendapatkan prosentase kecocokan tempat kos yang direkomendasikan sesuai dengan kriteria.

Kata kunci: kost, Electre, SAW, kriteria

cc) (7) 5 - $\left[\begin{array}{l}\text { This is an open access article distributed under the Creative Commons Attribution License, which permits unrestricted use, } \\ \text { distribution, and reproduction in any medium, provided the original work is properly cited. (02018 by author and IJSE-Indonesian }\end{array}\right.$ EY NC SA Journal on Software Engineering.

\section{A. PENDAHULUAN}

Semakin banyaknya lembaga pendidikan atau bahkan perguruan tinggi, salah di kota Purwokerto menuntut masyarakat sekitar untuk bersiap dengan datangnya warga dari luar kota purwokerto yang membutuhkan tempat tinggal, yang kemudian dikenal dengan istilah kost. Istilah kost sendiri berasal dari bahasa Belanda yakni In de kost. Menurut kamus Besar Bahasa Indonesia, indekos sendiri berarti tinggal di rumah orang lain dengan atau tanpa makan dengan membayar setiap bulan.

Beberapa perguruan tinggi memiliki jarak yang saling berdekatan, seperti misalnya kampus Universitas Jenderal Soedirman yang menjadi salah satu universitas negeri di kota Purwokerto dan menjadi incaran calon mahasiswa dari luar kota bahkan luar pulau Jawa berdekatan dengan kampus AMIK BSI Purwokerto, STMIK AMIKOM dan Institut Agama Islam Negeri (IAIN) Purwokerto. Sehingga bagi warga pendatang yang melanjutkan pendidikannya di Purwokerto salah satu pilihan untuk tetap tinggal dan melanjutkan studinya dengan cara kos atau mengkontrak rumah atau bahkan membeli rumah. Namun dari kebanyakan mahasiswa yang ada di Purwokerto dan berasal dari luar kota memilih untuk tinggal dengan cara nge-kos.

Akan tetapi dengan banyaknya kost yang ada di daerah Purwokerto, khusunya di daerah sekitar kampus-kampus tersebut terkadang membuat mahasiswa suka berpindah-pindah tempat kos. Dalam menentukan tempat kos, masing-masing individu mempunyai selera yang berbeda. Fasilitas yang disediakan oleh pemilik kos pun berbeda antara satu dengan yang lain. Faktor-faktor inilah yang nantinya menjadi pertimbangan calon penghuni kost. Beberapa pertimbangan yang digunakan oleh calon penghuni kos antara lain faktor lingkungan kos, harga kos, fasilitas, referensi, lokasi, keamanan dan pelayanan (Hajar, 2012). Selain itu banyak yang mempertimbangkan batasan jam malam, 
jarak kos ke kampus serta luas kamar yang terkadang menyulitkan pencari kos (Sugianto, 2016). Oleh karena tu perlu dibangun suatu sistem pendukung keputusan yang dapat membantu mahasiswa dan calon mahasiswa dalam memilih tempat kos yang tepat dan sesuai dengan kebutuhan.

Metode SAW pernah digunakan dalam penentuan rumah kos dengan judul "Pemilihan Kost di Sekitas Universitas Brawijaya menggunakan metode Analitial Hierarchy Process (AHP) dan Simple Additive Wegthing (SAW) (Primanda, Santoso, \& Afirianto, 2017). Hasil dari penelitian tersebut adalah dengan adanya sistem seperti ini akan memudahkan mahasiswa untuk menentukan kos. Pada penelitian yang selanjutnya dengan judul "Metode Elimination and Choice Translation Reality (ELECTRE) dan Fuzzy Kurva-S Untuk Pemilihan Rumah Di Kota Medan menghasilkan kesimpulan bahwa proses pemilihan dapat dilakukan menggunakan sistem pendukung keputusan sesuai dengan kriteria yang telah ditentukan dan metode ELECTRE dapat digunakan untuk membantu pengambilan keputusan dalam pemilihan rumah untuk menghasilkan keputusan yang akurat dan cepat (Situmorang, 2017).

\section{B. TINJAUAN PUSTAKA}

1. Kost

Menurut Kamus Besar Bahasa Indonesia (KBBI) istilah kost mempunyai arti tinggal di rumah orang lain dengan atau tanpa makan (dengan membayar setiap bulan) atau dengan kata lain memondok. Kata "kost" berasal dari frasa Bahasa Belanda yakni "In de Kost".

\section{Metode SAW}

Berdasarkan namanya, metode Simple Additive Weigthing (SAW) dapat diartikan sebagai metode pembobotan yang sederhana atau penjumlahan terbobot pada penyelesaian masalah dalam sebuah sistem pendukung keputusan. Konsep dari metode ini adalah dengan menggunakan rating kinerja pada setiap alternatif pada semua atribut (Nofriansyah, 2016).

Adapun algoritma penyelesaian metode ini yaitu sebagai berikut:

1. Mendefinisikan terlebih dahulu kriteriakriteia yang akan dijadikan sebagai tolok ukur penyelesaian masalah.

2. Menormalisasi setiap nilai alternatif pada setiap atribut dengan cara menghitung nilai rating kinerja.

3. Menghitung nilai bobot preferensi pada setiap alternatif yang sudah ditentukan.

4. Melakukan perankingan

\section{Metode ELECTRE}

Menurut Joko dan Bernoider dalam (Situmorang, 2017), ELECTRE merupakan suatu metode pengambilan keputusan multikriteria yang berdasarkan pada konsep outranking dan menggunakan perbandingan berpasangan dari masing-masing alternatif pada setiap kriteria yang sesuai.

Metode ELECTRE digunakan apabila kondisi alternatif kurang sesuai dengan kriteria yang ditentukan kemudian dihilangkan/dieliminasi sehingga menghasilkan alternatif yang sesuai dengan keinginan. Dengan kata lain, ELECTRE digunakan untuk kasus-kasus dengan banyak altenatif namun hanya sedikit kriteria yang dilibatkan.

Menurut situmorang (Situmorang, 2017), Suatu alternatif dikatakan mendominasi alternatif yang lainnya jika satu atau lebih kriterianya melebihi (dibandingkan dengan kriteria dari alternatif yang lain) dan sama dengan kriteria lain yang tersisa.

Langkah-langkah yang dilakukan dalam penyelesaian masalah menggunakan metode ELECTRE adalah sebagai berikut:

Langkah 1: Melakukan Normalisasi Matrik Keputusan

Dalam prosedur ini, setiap atribut diubah menjadi nilai yang comparable. Untuk menormalisasi nilai xy dapat dilakukan dengan menggunakan rumus:

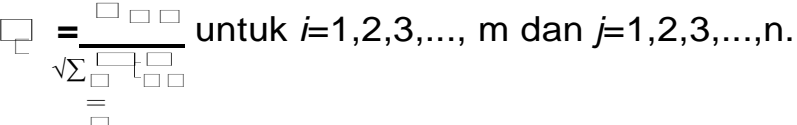

Sehingga didapat matriks B hasil normalisasi,

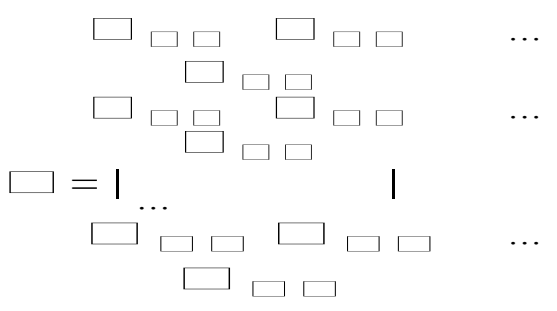

Dimana nilai $\mathrm{R}$ merupakan nilai matriks yang sudah dinormalisasi, dengan $m$ sebagai alternatif, $n$ sebagai kriteria dan $r$ sebagai nilai normalisasi pengukuran pilihan dari alternatif ke-i yang ada hubungannya dengan kriteria kej.

Langkah 2: Menentukan nilai bobot pada matrik yang telah dinormalisasi. 
Apabila matrik sudah dinormalisasi, selanjutnya masing-masing kolom dari matriks $\mathrm{R}$ dikalikan 
dengan bobot-bobot (wj) yang sudah ditentukan oleh pembuat keputusan. Sehingga diperoleh nilai weighted normalized matrix yaitu $V=R W$ dan ditulis sebagai berikut:

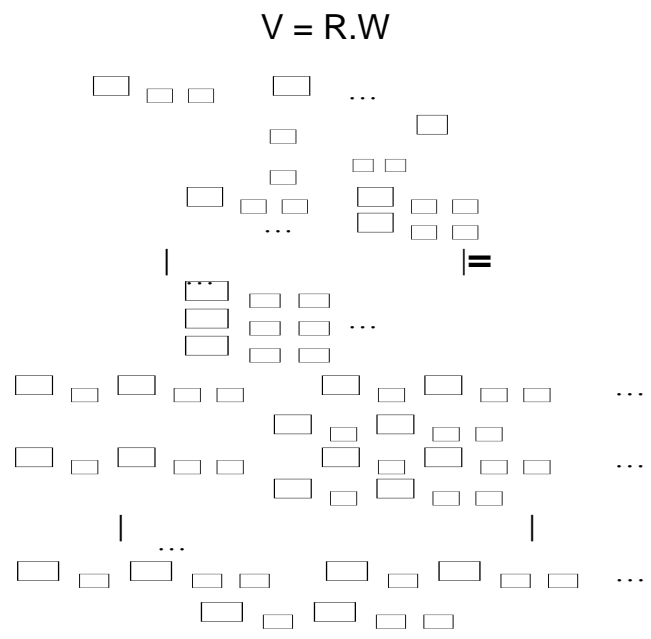

Dimana W adalah

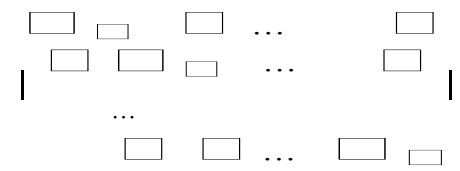

Langkah 3: Menentukan himpunan concordance dan discordance

Untuk masing-masing pasangan dari alternatif $\mathrm{k}$ dan i, kumpulan j kriteria dibagi menjadi dua bagian himpunan, yakni himpunan concordance dan himpunan discordance. Kriteria dalam alternatif yang termasuk dalam concordance .

Untuk masing-masing pasang dari alternatif $k$ dan i $\left(k, l=1,2,3, \ldots, m\right.$ dan $\left.k^{\wedge} l\right)$ kumpulan j kriteria dibagi menjadi dua bagian himpunan, yaitu himpunan concordance dan himpunan discordance. Sebuah kriteria dapat dikatakan sebagai alternatif yang termasuk concordance jika: $\square \square \square=j, \square \square \square>\square \square \square$, untuk $j=$ $1,2,3, \ldots, n$

Sebaliknya, himpunan concordance mempunyai komplemen yaitu himpunan discordance. Himpunan dikatakan discordance apabila

$$
\begin{aligned}
& \square \square=\{j, \square \square \square< \\
& \square \square \square \text {, untuk } j=1,2,3, \ldots, n
\end{aligned}
$$

Langkah 4: Hitung matriks concordance dan discordance

a. Menghitung nilai matriks concordance Dalam menghitung nilai dari elemen matrik concordance dilakukan dengan cara membagi secara maksimum selisih kriteria yang termasuk dalam himpunan discordance dengan maksimum selisih nilai kriteria secara keseluruhn dengan rumus:

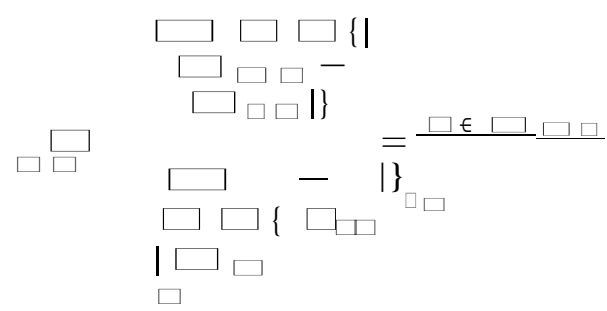

Langkah 5: menentukan matrik dominan concordance dan discordance

a. Menghitung matriks domain concordance

Matriks $F$ sebagai matriks dominan concordance dapat dibangun dengan bantuan nilai threshold, yaitu dengan membandingkan setiap nilai elemen matriks concordance dengan nilai threshold.

$$
\square \square \square \geq \square
$$

Dengan nilai threshold (c) adalah :

$$
=\frac{\sum \square \sum \square=\square}{=1} \square
$$

Sehingga elemen matriks $\mathrm{F}$ ditentukan sebagai berikut :

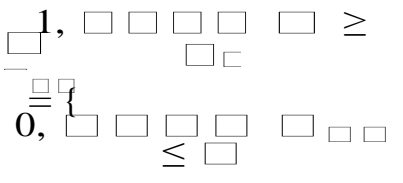

b. Menghitung matriks domain discordance

Matriks $G$ sebagai matriks dominan discordance dapat dibangun dengan bantuan nilai threshold $d$ :

$$
\square \frac{\sum_{\square} \sum_{\square=} \square \square \square}{1} \square
$$

menjumlahkanbobot-bobot nilai yang ada didalam matrik concordance dengan rumus:

$$
\square \square \square=\sum_{\square \epsilon \square \square \square} \square \square
$$

b. Menghitung nilai matriks discordance Untuk menghitung nilai dari elemen matriks discordance dilakukan dengan 
$\square(\square-1)$

Dan elemen matriks $\mathrm{G}$ ditentukan sebagai berikut :

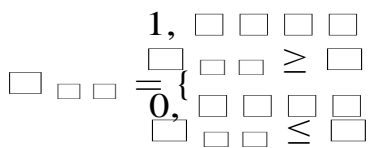

Langkah 6: menentukan aggregate dominance matrix

Matriks E sebagai aggregate dominance matriks adalah matriks yang setiap elemennya merupakan perkalian antara elemen matriks $\mathrm{F}$ dengan elemen matriks $G$ yang bersesuaian secara matematis dapat dinyatakan sebagai :

$$
\begin{gathered}
\square \square \square= \\
\square \square \square \square \square \\
\square \square
\end{gathered}
$$


Langkah 7: Eliminasi alternatif yang less favourable

Matriks E memberikan urutan pilihan dari setiap alternatif, yaitu bila ekt=1 maka alternatif $\mathrm{Ak}$ merupakan alternatif yang lebih baik daripada Al. Sehingga, baris dalam matriks $E$ yang memiliki jumlah eki=1 paling sedikit dapat dieliminasi. Dengan demikian alternatif terbaik adalah alternatif yang mednominasi alternatif lainnya.

\section{Sistem Pendukung Keputusan}

Menurut frieyadie dalam (Frieyadie, 2016), sistem pendukung keputusan sebagai sistem berbasis komputer yang terdiri dari tiga komponen yang saling berinteraksi yaitu sistem bahasa (bagaimana memberikan mekanisme untk berkomunikasi antara pengguna dan komponen sistem pendukung yang lainnya), sistem pengetahuan (repositori pengetahuan domain masalah yang ada pada sistem pendukung keputusan atau sebagai data atau sebagai prosedur), dan sistem pemrosesan masalah (untuk melihat hubungan antara dua komponen lainnya yang terdiri dari satu atau lebih kemungkinan manipulasi secara umum yang diperlukan dalam pengambilan keputusan).

\section{HASIL DAN PEMBAHASAN}

Berdasarkan kriteria rumah kost yang sering diminati oleh calon penghuninya sesuai dengan berdasarkan bobot yang telah ditentukan ke dalam bilangan fuzzy. Jenis kriteria yang digunakan dalam penelitian ini adalah lokasi, harga, fasilitas dan keamanan. Alternatif dari setiap kriteria diubah kedalam matriks $\mathrm{X}$ dengan data:

$$
\begin{aligned}
& \begin{array}{llll}
5 & 3 & 5
\end{array} \\
& \overline{5}\left[\begin{array}{cccc}
4 & 4 & 5 & 3 \\
5 & 4 & 4
\end{array}\right] \\
& \begin{array}{llll}
4 & 3 & 5 & 5
\end{array}
\end{aligned}
$$

Diberikan Nilai Bobot (W)

$W=\left[\begin{array}{llll}5 & 4 & 3 & 5\end{array}\right]$

\section{Metode SAW}

Langkah penyelesaian untuk kasus diatas adalah:

a. Menormalisasi setiap alternatif pada setiap atribut dengan menghitung nilai rating kinerja.

$$
\begin{aligned}
& R_{11}=\frac{5}{\max \{5,4,5,4\}}=\frac{5}{5}=1 \\
& \mathrm{R}_{21}=\frac{4}{\max \{5,4,5,4\}}=\frac{4}{5}=0,8 \\
& \mathrm{R}_{31}=\frac{5}{\max \{5,4,5,4\}}=\frac{5}{5}=1 \\
& \mathrm{R}_{41}=\frac{4}{\max \{5,4,5,4\}}=\frac{4}{5}=0,8 \\
& \mathrm{R}_{12}=\frac{3}{\max (3,4,5,3)}=\frac{3}{5}=0,6 \\
& \mathrm{R}_{22}=\frac{4}{\max (3,4,5,3)}=\frac{4}{5}=0,8 \\
& \mathrm{R}_{32}=\frac{5}{\max (3,4,5,3)}=\frac{5}{5}=1 \\
& \mathrm{R}_{42}=\frac{3}{\max (3,4,5,3)}=\frac{3}{5}=0,6 \\
& \mathrm{R}_{13}=\frac{5}{\max \{5,5,4,5)}=\frac{5}{5}=1 \\
& \mathrm{R}_{23}=\frac{5}{\max (5,5,4,5)}=\frac{5}{5}=1 \\
& \mathrm{R}_{33}=\frac{4}{\max (5,5,4,5)}=\frac{4}{5}=0,8 \\
& R_{43}==\frac{5}{\max (5,5,4,5)}=\frac{5}{5}=1 \\
& \mathrm{R}_{14}=\frac{5}{\max \{5,3,4,5\}}=\frac{5}{5}=1 \\
& \mathrm{R}_{24}=\frac{3}{\max \{5,3,4,5\}}=\frac{3}{5}=0,6 \\
& R_{34}=\frac{4}{\max \{5,3,4,5\}}=\frac{4}{5}=0,8 \\
& R_{44}=\frac{5}{\max \{5,3,4,5\}}=\frac{5}{5}=1
\end{aligned}
$$

Maka matrik kinerja ternormalisasinya adalah sebagai berikut:

$$
R=\left[\begin{array}{cccc}
1 & 0,6 & 1 & 1 \\
0,8 & 0,8 & 1 & 0,6 \\
1 & 1 & 0,8 & 0,8 \\
0,8 & 0,6 & 1 & 1
\end{array}\right]
$$

b. Menghitung nilai bobot preferensi masingmasing alternatif (Vi)

\section{Nilai Vi dari tipe alternatif 1 :}

$$
\begin{aligned}
& V_{1}=\left(W_{1}{ }^{*} R_{11}\right)+\left(W_{2}{ }^{*} R_{12}\right)+\left(W_{3}+R_{13}\right)+\left(W_{4}{ }^{*} R_{14}\right) \\
& =\left(5^{*} 1\right)+\left(4^{*} 0,6\right)+\left(3^{*} 1\right)+\left(5^{*} 1\right) \\
& =15,4 \\
& V_{2}=\left(W_{1}{ }^{*} R_{21}\right)+\left(W_{2}{ }^{*} R_{22}\right)+\left(W_{3}+R_{23}\right)+\left(W_{4}{ }^{*} R_{24}\right) \\
& =\left(5^{\star} 0,8\right)+\left(4^{*} 0,8\right)+\left(3^{*} 1\right)+\left(5^{*} 0,6\right) \\
& =13,2 \\
& \mathrm{~V}_{3}=\left(\mathrm{W}_{1}{ }^{*} \mathrm{R}_{31}\right)+\left(\mathrm{W}_{2}{ }^{*} \mathrm{R}_{32}\right)+\left(\mathrm{W}_{3}+\mathrm{R}_{33}\right)+\left(\mathrm{W}_{4}{ }^{*} \mathrm{R}_{34}\right) \\
& =\left(5^{\star} 1\right)+\left(4^{*} 1\right)+\left(3^{*} 0,8\right)+\left(5^{\star} 0,8\right) \\
& =15,4 \\
& \mathrm{~V}_{4} \\
& \left(\mathrm{~W}_{1}{ }^{*} \mathrm{R}_{41}\right)+\left(\mathrm{W}_{2}{ }^{*} \mathrm{R}_{42}\right)+\left(\mathrm{W}_{3}+\mathrm{R}_{43}\right)+\left(\mathrm{W}_{4}{ }^{*} \mathrm{R}_{44}\right) \\
& =\left(5^{\star} 0,8\right)+\left(4^{\star} 0,6\right)+\left(3^{\star} 1\right)+\left(5^{\star} 1\right) \\
& =14,4
\end{aligned}
$$

c. Melakukan perankingan berdasarkan nilai bobot preferensinya

Berdasarkan perhitungan $\mathrm{V}_{i}$, terlihat ada dua nilai yang sama yakni 15,4 pada $V_{1}$ dan $V_{3}$ yang akan dipilih sebagai pemilihan tempat kos yang sesuai dengan kriteria yang diinginkan. Hal ini dapat diartikan bahwa Green Gardenia dan Dimensi Kos menjadi tujuan utama para mahasiswa untuk dijadikan tempat kos. 


\section{Metode ELECTRE}

Langkah penyelesaiannya untuk kasus diatas adalah:

a. Normalisasi matriks keputusan yaitu:

$$
R=\left[\begin{array}{cccc}
0,5522 & 0,3906 & 0,5241 & 0,5774 \\
0,4417 & 0,5208 & 0,5241 & 0,3464 \\
0,5522 & 0,6509 & 0,4193 & 0,4619 \\
0,4417 & 0,3906 & 0,5241 & 0,5774
\end{array}\right.
$$

b. Pembobotan pada matriks yang telah dinormalisasi

$$
\text { 2,7608 1,5623 1,5724 2,8868 }
$$

$$
\mathrm{V}=\left[\begin{array}{cccc}
2,2086 & 2,0830 & 1,5724 & 1,7321 \\
2,7608 & 2,6038 & 1,2579 & 2
\end{array}\right], 3094
$$

c. Menentukan himpunan concordance dan discordance

1) Concordance

Himpunan concordance yang dihasilkan adalah:

\begin{tabular}{|c|c|}
\hline C12 & $\{1,3,4\}$ \\
\hline C13 & $\{1,3,4\}$ \\
\hline c14 & $\{1,2,3,4\}$ \\
\hline C21 & $\{2,3\}$ \\
\hline C23 & $\{3\}$ \\
\hline C24 & $\{1,2,3\}$ \\
\hline C31 & $\{1,2\}$ \\
\hline C32 & $\{1,2,4\}$ \\
\hline C34 & $\{1,2\}$ \\
\hline C41 & $\{2,3,4\}$ \\
\hline C42 & $\{1,3,4\}$ \\
\hline C43 & $\{3,4\}$ \\
\hline
\end{tabular}

2) Discordance

Himpunan discordance yang dihasilkan adalah:

\begin{tabular}{|c|c|}
\hline D12 & $\{2\}$ \\
\hline D13 & $\{2\}$ \\
\hline D14 & \{\} \\
\hline D21 & $\{1,4\}$ \\
\hline D23 & $\{1,2,4\}$ \\
\hline D24 & $\{4\}$ \\
\hline D31 & $\{3,4\}$ \\
\hline D32 & $\{3\}$ \\
\hline D34 & $\{3,4\}$ \\
\hline D41 & $\{1\}$ \\
\hline D42 & $\{2\}$ \\
\hline D43 & $\{1,2\}$ \\
\hline
\end{tabular}

d. Menghitung matriks concordance dan discordance

a. Matrik concordance

\begin{tabular}{|c|c|c|c|}
\hline- & 13 & 13 & 17 \\
\hline 7 & - & 3 & 12 \\
\hline 9 & 14 & - & 9 \\
\hline 12 & 13 & 8 & - \\
\hline
\end{tabular}

b. Matrik discordance

\begin{tabular}{|c|c|c|c|}
\hline- & 0,451 & 1 & 0 \\
\hline 1 & - & 1 & 1 \\
\hline 0,5544 & 0,5447 & - & 0,5544 \\
\hline 1 & 0,451 & 1 & - \\
\hline
\end{tabular}

e. Menentukan threshold matrik dominan concordance dan discordance

Nilai threshold dari matrik concordance dihitung dari penjumlahan seluruh elemen matrik dibagi dengan ukuran matrik, sehingga didapat matrik cocordance-nya adalah:

$$
\mathrm{F}=\left[\begin{array}{cccc}
- & 1 & 1 & 1 \\
0 & - & 0 & 1 \\
0 & 1 & - & 0 \\
1 & 1 & 0 & -
\end{array}\right]
$$

Sedangkan untuk matrik discordance-nya adalah:

$$
G=\left[\begin{array}{llll}
- & 0 & 1 & 0 \\
0 & - & 1 & 1 \\
1 & 0 & - & 0
\end{array}\right]
$$

f. Menentukan agregate dominance matrik

$$
\begin{aligned}
& E=F \times G
\end{aligned}
$$

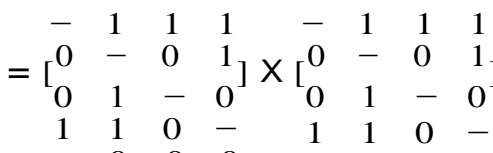

$$
\begin{aligned}
& \begin{array}{llll}
1 & 1 & 0 & - \\
- & 0 & 0 & 0
\end{array} \\
& =\left[\begin{array}{cccc}
0 & - & 0 & 0 \\
0 & 0 & - & 0 \\
0 & 0 & 0 & -
\end{array}\right]
\end{aligned}
$$

Karena nilai $\mathrm{E}=0$, maka dipakai cara menjumlahkan nilai pada baris

\begin{tabular}{|c|c|c|c|c|c|}
\hline Alternatif & & & & & $\begin{array}{c}\text { Hasil } \\
\text { Akhir }\end{array}$ \\
\hline A1 & 2,7608 & 1,5623 & 1,5724 & 2,8868 & 8,7822 \\
\hline A2 & 2,2086 & 2,0830 & 1,5724 & 1,7321 & 7,5961 \\
\hline A3 & 2,7608 & 2,6038 & 1,2579 & 2,3094 & 8,9319 \\
\hline A4 & 2,2086 & 1,5623 & 1,5724 & 2,8868 & 8,2301 \\
\hline
\end{tabular}

g. Eliminasi alternatif yang less favourable Matriks E memberikan urutan pilihan dari setiap alternatif, yaitu bila $e_{k l}=1$ maka alternatif $A_{k}$ merupakan alternatif yang lebih baik dari pada $A$. Sehingga baris dalam matriks $E$ yang memiliki jumlah $e_{k l}=1$ paling sedikit dapat dieliminasi.

Namun, karena $e_{k l} \neq 1$ maka nilai tiap baris pada langkah 2 dijumlahkan, dan nilai yang paling tinggi adalah alternatif terbaik. Alternatif terbaik adalah Dimensi Kos dengan nilai 8,9319, sehingga Dimensi Kos terpilih untuk menjadi tempat kos para mahasiswa.

\section{KESIMPULAN}

Berdasarkan penelitian yang telah dilakukan dan melakukan perhitungan dengan metode SAW dan ELECTRE maka dihasilkan kesimpulan bahwa:

a. Proses pemilihan kos dapat dilakukan dengan menggunakan sistem pendukung keputusan yang sesuai dengan kriteria yang telah ditetapkan.

b. Dengan menggunakan Metode SAW dan ELECTRE didapatkan hasil yang hampir sama, dimana metode SAW memberikan alternatif pada Green Gardenia dan Dimensi sebagai tujuan utama pencarian kos, kemudian metode 
ELECTRE menetapkan Kos Green Gardenia sebagai alternatif terbaik penentuan kos di sekitar AMIK BSI Purwokerto.

\section{REFERENSI}

[1] Frieyadie. (2016). Penerapan Metode Simple Additive Weight (SAW) Dalam Sistem Pendukung Keputusan Promosi Kenaikan Jabatan. Jurnal Pilar Nusa Mandiri, 7(1), 3745.

[2] Hajar, Si. dkk. (2012). Faktor-Faktor Yang Memengaruhi Keputusan Mahasiswa Dalam Memilih Rumah Kost. Agustus, 1(1), 25-31.

[3] Nofriansyah, D. (2016). Modul: Sistem Pendukung Keputusan.

[4] Primanda, P. A., Santoso, E., \& Afirianto, T. (2017). Pemilihan Kost di Sekitar Universitas Brawijaya menggunakan Metode Analitycal Hierarchy Process ( AHP) dan Simple Additive Weighting ( SAW ). Jurnal Pengembangan Teknologi Informasi Dan IImu Komputer, 2(6), 2094-2103.

[5] Situmorang, D. Z. (2017). Metode Elimination and Choice Translation Metode Elimination and Choice Translation Reality ( ELECTRE ) dan Fuzzy Kurva-S Untuk Pemilihan Rumah di Kota Medan, (November 2016).

[6] Sugianto, D. (2016). Sistem Pendukung Keputusan Pemilihan Tempat Kost Khusus Mahasiswa dengan Metode AHP dan TOPSIS Berbasis Web ( Studi Kasus: Kota Pontianak ). Sistem Dan Teknologi Informasi, 1(Sistem Infofiamasi Geografis), 1-6. 